rev.relac.int.estrateg.segur.5(1):83-100,2010

\title{
DERECHOS HUMANOS, PRODUCCIÓN Y REPRODUCCIÓN DE LA POBREZA: INCIDENCIA DEL TRATAdO de LIBRE COMERCIO CANADÁ-COLOMBIA
}

(Análisis de los corteros de caña de azúcar)

Diego Andrés Guevara Fletcher*

\section{RESUMEN}

El siguiente artículo argumenta cómo el Tratado de Libre Comercio (TLC) entre Canadá y Colombia, iniciado el 21 de noviembre de 2008, aumentará las condiciones de vulnerabilidad de la población dedicada al corte de caña de azúcar en el departamento del Valle del Cauca, Colombia. En este sentido, el poder de los organismos internacionales y el de las empresas multinacionales contribuirán a la violación de los Derechos Humanos manteniendo un orden global injusto que ahonda las condiciones de pobreza de las personas que ejercen estas actividades.

Palabras clave: Derechos Humanos, pobreza, Tratado de Libre Comercio, desplazamiento forzado, caña de azúcar.

\footnotetext{
*Economista colombiano, Msc. en economía y doctorando en Ciencias Sociales FLACSO-Argentina. Profesor asistente de la Facultad de economía de la Escuela Colombiana de Ingeniería, Julio Garavito. Correo electrónicodiego.guevara@escuelaing.edu.co
} 


\begin{abstract}
The following article alleges how the Free Trade Agreement (FTA) started on November 21, 2008 between Canada and Colombia, will increase the vulnerability conditions of the people harvesting sugar cane, in the Department of Valle del Cauca, Colombia.

In this sense, the power of the international organizations and of the multinational companies will contribute to the violation of Human Rights, maintaining an unjust global order that deepens the poverty conditions of the people that do that kind of work.
\end{abstract}

Key Words: Human Rights, poverty, Free Trade Agreement, forced displacement, sugar cane

\title{
INTRODUCCIÓN
}

El presente artículo argumenta que el acuerdo del Tratado de Libre Comercio (TLC) entre Canadá y Colombia, firmado el 21 de noviembre de 2008, consentirá que el Estado colombiano y el poder de los organismos internacionales canadienses -en la persecución de sus intereses- mantengan un orden global injusto que contribuye de manera significativa a la producción de la pobreza y a la violación de los Derechos Humanos en la población socialmente vulnerable en Colombia.

Para demostrar lo anterior, se discute la manera en la cual la industria azucarera en el país actúa como industria oligopólica que, al imponer sus lógicas en materia de capital y competitividad en el área de Florida, en el Valle del Cauca, desmejora el bienestar de los corteros de caña que trabajan en ellas. Además de lo anterior, sus lógicas de actuación incluyen a la población desplazada por el conflicto armado en el país, que no tienen alternativa -en sus sitios de recepción- de insertarse en otras actividades laborales.

Por lo tanto, pude decirse que el Estado canadiense viola los Derechos Humanos y acentúa la producción y reproducción de la pobreza de manera indirecta, en el sentido de que ratifica tratados que buscan consolidar intereses económicos de intercambio comercial entre agentes nacionales y extranjeros en posiciones dominantes, sobre las necesidades y deficiencias en términos de bienestar de una población especifica, como en este caso lo es la población forzosamente desplazada.

\section{INDAGACIONES PRELIMINARES}

\section{Relaciones de Comercio internacional}

El ministro de Relaciones Exteriores de Canadá para las Américas ha expresado que la región se constituye en una zona especial de interés para Canadá, lo cual se evidencia en el hecho de las importantes inversiones realizadas que superan en cinco veces a las efectuadas en Asia.

Existen actualmente varios tratados entre el país del norte y otros del continente americano. Entre ellos podemos mencionar el TLC entre Canadá y Costa Rica, que entró en vigencia el 1 de noviembre 
de 2002. Dentro de los objetivos de este convenio se destaca la importancia de promover, facilitar y consolidar la integración de Costa Rica con el resto del mundo. Desde la entrada en vigencia del acuerdo ha habido un crecimiento de las exportaciones costarricenses a ese mercado, al igual que las importaciones; sin embargo, sectores agrícolas como el del arroz han experimentado una disminución de su precio, ocasionando la migración de pobladores que se dedicaban a esta actividad hacia otros centros de producción dentro del país centroamericano. De igual manera, diversas comunidades indígenas se han manifestado en contra de su promulgación, alegando afectaciones en la biodiversidad e identidad cultural.

El acuerdo firmado con el gobierno del Perú, que entró en vigencia el pasado 1 de agosto de 2009, es otro de los convenios efectuados en los últimos años en la región. Este TLC busca incrementar el intercambio comercial y reducir la pobreza, además de dotar de una fuerte protección a los derechos de los trabajadores, según la secretaria de Asuntos Exteriores y Comercio Exterior de Canadá.

En Colombia, partir de la década de los noventa, con el cambio de paradigma económico de apertura al resto del mundo, bajo el impulso del entonces Presidente Cesar Gaviria, produjo notables incrementos sobre todo en el intercambio comercial con Canadá.

Entre 1990 y 1995 las exportaciones canadienses de bienes y servicios hacia Colombia se incrementaron en un $77 \%$. Lo propio ocurrió con las exportaciones colombianas hacia Canadá: se incrementaron en un sorprendente 180\%, comandada especialmente por productos agrícolas como frutas frescas, banano café y azúcar. Para 1995, las exportaciones colombianas alcanzaron 270 millones de dólares. A partir de este quinquenio, la relación comercial bilateral se ha sostenido con leves descensos, como el registrado en el año 1997, diversificándose a productos tales como cartones, tuberías, joyerías y elementos quirúrgicos.

En el cuadro 1 se presenta la relación de intercambio comercial entre Colombia y Canadá entre los años 2002 y 2007. Las exportaciones en el periodo mencionado muestran para Colombia un notorio incremento del orden del $62 \%$. Las importaciones canadienses se elevaron en más del 162\%. La balanza comercial, por lo tanto, es deficitaria para todo el periodo de tiempo presentado; sin embargo, la variación del crecimiento porcentual del crecimiento global es positivo y creciente, a excepción del año 2006.

\section{Cuadro 1}

Intercambio comercial Colombia-Canadá - Millones de U\$ FOB

\begin{tabular}{|c|c|c|c|c}
\hline Años & Exportaciones & Importaciones & $\begin{array}{c}\text { Balanza } \\
\text { comercial }\end{array}$ & $\begin{array}{c}\text { Variación \% } \\
(\mathbf{E}+\mathbf{l})\end{array}$ \\
\hline 2002 & 164.261 & 246.757 & -82.497 & \\
\hline 2003 & 176.502 & 287.749 & -111.247 & 13 \\
\hline 2004 & 156.371 & 337.524 & -181.153 & 6.4 \\
\hline 2005 & 297.973 & 389.315 & -91.342 & 28.1 \\
\hline 2006 & 275.148 & 500.650 & -225.502 & 11.4 \\
\hline 2007 & 266.242 & 648.804 & -382.562 & 15.2 \\
\hline
\end{tabular}

Fuente: DANE 
Según el Departamento Administrativo Nacional de Estadísticas (DANE), Los principales productos de exportación de Colombia en el año 2007 fueron, en su orden de importancia: carbón (42\%); café (31.6\%); además de flores y azúcar con el $4.1 \%$ del total.

Por el lado de las importaciones, según el DANE, entre 2006 y 2007, resaltan los bienes de maquinaria y equipos con un incremento del orden de $73.4 \%$; armas con un aumento de $230.5 \%{ }^{1}$ y el de bienes agropecuarios en $46 \%$. Para el año 2009, el total de las importaciones procedentes de Canadá registró el $\%$, Ilegando al noveno lugar en importancia.

Las inversiones canadienses en Colombia se concentran principalmente en los sectores de telecomunicaciones (Bell Canada International, Nortel Networks, Teleglobe), hidrocarburos (Vanguard Oil) y energía (Enbridge, Nexen), los cuales han crecido de forma sostenida desde la década de los noventa. Durante los últimos años, las empresas de origen canadiense también han invertido en las áreas relacionadas con productos agro-alimentarios, la explotación de minas y gas y la fabricación de papel y cartón. Claramente, estas inversiones están encaminadas a la exportación colombiana de bienes básicos.

Según el Banco de la República, y cálculos adelantados por Proexport, en el año 2007 la inversión canadiense en Colombia llegó a U\$8 millones. Para el año 2009 alcanzó los U\$51.9 millones. Por todo lo anterior, la inversión del país del norte creció significativamente. Sin embargo, el valor es aún bajo comparado con otros países del mundo².

Hay que resaltar que Canadá representa el $1.1 \%$ del total de las exportaciones de Colombia al mundo, lo cual, en términos del volumen comercial, no es significativo. Sin embargo, al aprobar el TLC cabría esperar importantes incrementos a la luz de los planteamientos comerciales que trae implícito este tipo de acuerdos. Más allá de los impactos en términos de intercambio entre los dos países y las insistencias del gobierno colombiano para su firma, debería también plantearse otra reflexión de tipo socio-político para entender de una mejor manera la conveniencia de este convenio.

\section{REFERENTE TEÓRICO}

La pobreza en el mundo ha persistido, no porque se carezca de medios suficientes para erradicarla. Según Pogge (2005 (a): 151), los ciudadanos y los gobiernos de los países ricos, al imponer el actual orden económico global, contribuyen de manera significativa a la producción y sostenimiento de la pobreza y, por consiguiente, comparten una responsabilidad moral e institucional, en la

\footnotetext{
${ }_{1}^{1}$ Paradójicamente a este rubro, Canadá es uno de los países que más ayuda ofrece en materia de cooperación, especialmente en derechos humanos, responsabilidad social corporativa y asistencia técnica con el comercio.

${ }^{2}$ El total de la inversión extranjera directa (IED) alcanzó para el año 2008 los U\$10.583.2 millones. Estados Unidos representó aproximadamente el 33\% del total.
} 
medida en que afectan las condiciones de millones de personas, especialmente en los países periféricos ${ }^{3}$.

Este autor sostiene que la violación de los Derechos Humanos se relaciona directamente con la imposición de los intereses de las empresas transnacionales de los países del centro, o de empresas nacionales que conforman las elites de los países llamados del tercer mundo que poseen intereses sobre las necesidades de los países de la periferia caracterizados, entre otras cosas, por la debilidad institucional de sus Estados-naciones.

En consecuencia, los pobres de los países en cuestión suelen ser privados de distintos tipos de derechos. En particular, los relacionados con el acceso a la tierra (que pocas veces les permite ser propietarios) y los de las políticas de instrucción que ubican las escuelas lejos de sus casas. Medio siglo atrás, los gobiernos tenían un mayor control sobre las condiciones económicas, políticas y sociales en sus propios países, y el Estado tenía la responsabilidad de garantizar los Derechos Humanos bajo la presunción de que solo él era competente y capaz de ejercer esta responsabilidad. Los gobiernos actuales, sus instituciones y sus representantes se convierten en muchos casos en ejemplos fehacientes de la falta de respeto oficial de los Derechos Humanos. Ello sucede, por ejemplo, promulgando o manteniendo leyes u órdenes normativas injustas, incluso al «abrigo de la ley» (Pogge, 2005 (b): 83).

La irracionalidad en el manejo de las privatizaciones, la falta de controles básicos al «libre comercio», así como la presencia excesiva de las corporaciones multinacionales en el control de la economía mundial han limitado las funciones básicas del Estado, particularmente en los países Ilamados del «sur», entre ellos Colombia. Esto permite entender que el Estado no es el único responsable de la violación de los Derechos Humanos ni el único garante de la seguridad de los ciudadanos. El sistema capitalista, con su mercado global, ha penetrado todas las actividades humanas, atentando permanentemente contra los derechos básicos de amplios grupos poblacionales. Anteriormente, el discurso se concentraba en la universalidad de los Derechos Humanos y sus fundamentos. Actualmente, el Estado y las fuerzas económicas refuerzan y justifican la violación de los derechos básicos de los individuos, lo que ha generado la necesidad de cambiar el enfoque sobre el discurso de los Derechos Humanos (Van Genugten y Pérez-Bustillo, 2001; Luna, 2007).

De modo complementario, diversos análisis históricos sobre el funcionamiento económico de la sociedad colombiana han identificado cómo la concentración del capital, la tierra y el poder político están en manos de una pequeña elite, así como de los intereses parcializados de entidades transnacionales como variables generadores de violencia en Colombia (Sarmiento, 2000; Machado, 2004). Por ende, la producción de la pobreza es considerada en este contexto como un fenómeno

\footnotetext{
${ }^{3}$ Pogge ha estimado que una transferencia de ingresos de $U \$ 300$ millones de millones en un año (a precios del año 2001) podría erradicar la pobreza de alrededor de 2.800 millones de personas en el mundo que viven con menos de U\$2 por día. Este monto es mucho menor que el gasto de defensa de los estados Unidos (US400 millones) o del presupuesto estimado de los «dividendos de paz» de los países más poderosos, resultado del final de la guerra fría (US477 millones de millones).
} 
complejo que obliga a la atención de las relaciones entre los diferentes procesos socio-económicos, histórico-políticos y étnico-culturales de la sociedad. En este sentido, no se puede hacer abstracción de las diferencias que se manifiestan por los intereses privados, hegemónicos y globalizantes ${ }^{4}$.

En esta línea de argumentación Thomas Pogge desarrolla su tesis consistente en que la pobreza mundial es una violación de los Derechos Humanos. Esto es consecuencia de sostener que no solo es injusta la acumulación originaria, sino que también lo es el orden institucional contemporáneo a nivel internacional, que contribuye a mantener inalterada y sin solución la situación de pobreza extrema de amplísimos sectores de la población mundial. Algunos de estos mismos países se hallan a la vanguardia de la defensa de los Derechos Humanos, porque la ambigüedad ética ya comentada les permite defender un orden internacional que equivale a una injusticia de facto, respondiendo a los intereses cambiantes de quienes poseen el capital, la tecnología, la tierra y los recursos naturales. ${ }^{5}$

\section{EL TLC COLOMBIA-CANADÁ}

El 21 de noviembre de 2008 se firmó el Tratado de Libre Comercio entre Colombia y Canadá. La firma del acuerdo se hizo en medio del encuentro entre el presidente Álvaro Uribe con el Primer Ministro del Canadá, Stephen Harper, momento en el cual los dos mandatarios fueron testigos de la puesta en marcha del acuerdo comercial.

Tanto Uribe como Harper también estuvieron en calidad de observadores en la suscripción de un acuerdo para evitar la doble tributación entre las dos naciones y otros convenios sobre cooperación en materia ambiental y laboral. Este TLC deberá ser ratificado por los congresos de los dos países. Además, en Colombia, deberá ser revisado por la Corte Constitucional.

En esencia, este tratado garantiza la exención de aranceles para el $97 \%$ de las exportaciones colombianas hacia Canadá. El jefe del equipo negociador del TLC con Canadá, Ricardo Duarte,

\footnotetext{
${ }^{4}$ Cimadamore (2005) ubica en un lugar de alta visibilidad a los agentes y estructuras que contribuyen a la producción mantenimiento y reproducción de la pobreza.

${ }^{5}$ El argumento de Rawls contra un principio de distribución global es que los factores responsables por la desigualdad y pobreza globales son, sobre todo, internos a las "sociedades cargadas», es decir, sociedades sujetas a circunstancias socioeconómicas y culturales desfavorables: "...creo que las causas de la riqueza de un pueblo y las formas que adopta residen en su cultura política y en las tradiciones religiosas, filosóficas y morales que sostienen la estructura básica de sus instituciones políticas y sociales, tanto como en la industriosidad y talentos cooperativos de sus miembros, todo ello sostenido a su vez por sus valores políticos.(...) Los elementos cruciales que hacen la diferencia son la cultura política, las virtudes políticas y la sociedad cívica del país, la probidad e industriosidad de sus miembros, su capacidad para la innovación, y mucho más. También es crucial la política poblacional del país: debe tener cuidado en no sobrecargar a su territorio y a su economía con una población mayor a la que puede sustentar...» (Rawls, 1999 En: de Vita, A. (2003:226).
} 
dijo que Colombia podrá acceder con preferencias arancelarias a un mercado que importa el $4.5 \%$ del total mundial, y que se posiciona como el quinto país en el mundo por su volumen de comercio.

Sin embargo, según la Red Colombiana de Acción Frente al Libre Comercio (RECALCA) se aduce que Canadá impone un impuesto al valor agregado del 7\% a todos los productos importados, además de colocar impuestos federales al consumo. Ninguno de estos obstáculos fue contemplado en la firma del tratado. De esta manera, la relación comercial no será del todo favorable para Colombia. Según varios observadores nacionales, el principal objetivo de este TLC no es el comercial, sino el de concentrar la exportación de materias primas básicas de bienes industriales. Esto puede disminuir la competitividad del país.

Para el caso que nos compete, -la industria azucarera en Colombia-, cabe anotar que este sector está conformado por empresas oligopolísticas (Espinal, Martínez, Beltrán 2005) ${ }^{6}$, aglutinadas en la Asociación de Cultivadores de Caña de Azúcar ASOCAÑA.

El azúcar, como negocio central del conglomerado, se ha desarrollado gradualmente mediante los procesos de expansión, diferenciación de producto, integración y diversificación. Como consecuencia de este desarrollo, es necesario entender que el negocio central se ha venido desplazando gradualmente del azúcar hacia otros productos de valor agregado. El crecimiento de las exportaciones y el uso intensivo de los diferentes productos asociados ha permitido disminuir la dependencia inicial, casi absoluta, del azúcar como producto básico dedicado al consumo directo, al punto que actualmente alrededor de $25 \%$ del azúcar que se produce se destina al consumo humano interno (CEPAL 2002). Esta diversificación está representada hacia otros productos tales como el bagazo y la cachaza para la fabricación de papel, mieles y el alcohol carburante. Su gran representatividad, tanto en los países, como en la región, la constituye su aporte al $1 \%$ del PIB nacional, $3 \%$ el PIB industrial y el $4 \%$ del PIB agrícola.

Ante las anteriores expectativas, y todavía sin conocerse el texto definitivo de este tratado, sí pueden observarse algunas cuestiones inherentes a la relación entre Estado-industria multinacional y la población rural en Colombia. En efecto, la participación del sector azucarero en el total de exportaciones colombianas hacia Canadá, como se muestra en el cuadro 2, pasa en el año 2000 de 93.601 toneladas, que significan el $13.6 \%$ del total de las exportaciones, a 33.900 toneladas con un $20 \%$ en el total de exportaciones y el consentimiento de ambos gobiernos a la inversión en este sector y al del biocombustible? .

\footnotetext{
${ }^{6}$ Estos autores demuestran cómo al evaluar el grado de concentración de la industria encuentran que los primeros establecimientos concentran el $55 \%$ del total de las ventas, por lo que la industria de fabricación y refinación de azúcar se considera un oligopolio «moderadamente» concentrado.

${ }^{7}$ El informe de ASOCAÑA 2007-2008 resalta cómo el azúcar constituye uno de los productos de mayor complejidad dentro de las negociaciones; el etanol, en cambio, tendría un acceso real a los mercados de EFTA y Canadá.
} 


\section{Cuadro 2}

\section{Destino de azúcar crudo de los ingenios en Colombia 2000-2007} (TMVC*)

\begin{tabular}{|l|l|l|l|l|l|l|l|l|}
\hline & $\mathbf{2 0 0 0}$ & $\mathbf{2 0 0 1}$ & $\mathbf{2 0 0 2}$ & $\mathbf{2 0 0 3}$ & $\mathbf{2 0 0 4}$ & $\mathbf{2 0 0 5}$ & $\mathbf{2 0 0 6}$ & $\mathbf{2 0 0 7}$ \\
\hline Canadá & 93.601 & 9.700 & 18.400 & 100.410 & 27.120 & 95 & 53.696 & 33.900 \\
\hline $\begin{array}{l}\text { \% del } \\
\text { total } \\
\text { países }\end{array}$ & 13.6 & 1 & 2 & 15.8 & 4.7 & 0.0002 & 18.1 & 20 \\
\hline
\end{tabular}

Fuente: ASOCAÑA. Cálculos del autor. *Toneladas métricas en su equivalente en volumen.

En materia de biocombustibles, el ministro de Minas y Energía de Colombia, Hernán Martínez, sostuvo en Canadá que el tema de los biocombustibles «...es un programa no tanto para producir energía, pero sí para producir empleo...» asegurando que «...va a tener una importante demanda en Estados Unidos y Europa en los planes 20/10 y 20/20 de la Comunidad Económica Europea...». Y concluyó con el espinoso tema de los Derechos Humanos de la siguiente manera: «...Colombia es el país que más ha estado en la mira pensando que nosotros violamos los Derechos Humanos y quiero que me digan un solo caso en el que el Estado como tal haya violado los Derechos Humanos. Ahora, puede que haya empresas que lo hagan y esas empresas se castigan. Puede que haya un general o un coronel de un ejército que en determinado momento haya cometido una falla, pero no es el Ejército, es una persona dentro del ejército....».

\section{Manifestación de la dirigencia sindical canadiense al TLC entre Colombia-Canadá}

[...] Los dirigentes sindicales canadienses manifestaron que luego de examinar la situación actual de Colombia en materia de Derechos Humanos y laborales, llegaron a la conclusión de que este TLC no va a ayudar al pueblo de Colombia. «Solamente va a recrudecer esa interminable lista de violaciones a los Derechos Humanos y laborales que ubican a Colombia como el lugar del mundo más peligroso para los sindicalistas, con 32 líderes sindicales asesinados nada más en lo que va de este año [2008].

Además, lamentaron que en Colombia no haya un marco jurídico que garantice plenos derechos de contratación colectiva, que menos del $5 \%$ de los trabajadores colombianos estén organizados en sindicatos, y que a los trabajadores públicos se les haya quitado cualquier posibilidad de negociar sus derechos, cuando en Canadá el 70\% de los trabajadores del sector público está sindicalizado.

«Al regresar a Canadá comunicaremos esta delicada situación a nuestros afiliados, a la opinión pública

\footnotetext{
${ }^{8}$ La entrevista en detalle se puede consultar en la edición digital de correo canadiense, disponible en http:// www.elcorreo.ca/elcorreo/story.php?story_id=6897 del 27 de marzo de 2008.
} 
canadiense, a nuestros gobiernos. Porque es inaceptable firmar un TLC entre Colombia y Canadá mientras la vida de los trabajadores sindicalistas esté en riesgo y sus derechos humanos y sindicales continúen siendo violados», añadieron en su declaración.

A la pregunta de qué tanto pueden incidir sus recomendaciones en la suerte del TLC con Canadá, señalaron que seguramente va a tener su incidencia negativa. De hecho, la comisión responsable de los asuntos de comercio y relaciones exteriores en el Parlamento canadiense ya se pronunció en contra de la firma del TLC con Colombia, hasta tanto este país no dé plenas garantías a los Derechos Humanos y sindicales. «El partido que hoy gobierna en Canadá y que negocia con Colombia el TLC, no tiene la mayoría en el Parlamento, y para las próximas elecciones vamos a adelantar una fuerte oposición a ese TLC; elecciones que es muy posible que el gobierno actual las pierda», puntualizaron.

"Nunca vamos a aceptar que el gobierno de Canadá firme un acuerdo sobre comercio con un país que niega el derecho fundamental de pertenecer a un sindicato. Solamente estaremos de acuerdo con un tratado de comercio justo, que incluya la justicia social, el respeto para los Derechos Humanos, derechos sindicales y el respeto para el ambiente. Y vamos a suministrar todo el material que hemos conseguido en nuestra visita a Colombia para probar que el tratado realmente es inconveniente», señaló Paul Moist, presidente del Sindicato Nacional de Empleados Públicos de Canadá.

El interés de convertir al país en una rica fuente de producción de etanol responde a las demandas internacionales de consumidores del mismo modo que, según la Organización Internacional del Azúcar (OIA) y F.O. Licht, ubicaron a Canadá en el año 2006 en el quinto lugar con 569 millones de litros, después de Brasil, Estados Unidos, la Unión Europea y China.

En este sentido, la producción de etanol en Colombia está exenta de IVA (16\%), y el impuesto de la sobretasa a la gasolina en el orden del (25\%), que puede ser al equivalente a U\$153 millones que no recauda el Estado y que incentiva a la producción adicional de los ingenios.

Sin embargo, para producir biodisel se necesita mezclar el aceite de palma con el etanol que se extrae de la caña de azúcar. Aquí es donde se explica la amalgama entre la fusión de los grandes latifundistas o empresarios agrícolas concentrados en los ingenios azucareros y el incentivo del Estado por la producción de otros monocultivos como el de palma africana. Además de esto, como lo señala Mondragón (2005) «...Tras la bonanza azucarera vino el auge de la palma aceitera; la palma aceitera llegó a Colombia en las manos de grandes propietarios que se aprovecharon de la tierra acumulada en regiones como el Magdalena medio, después del gran desplazamiento de campesinos que causó la violencia de 1946 a 1958. Luego la expansión de monocultivos para la producción de biocombustibles que fueron dejando campesinos, indígenas y afrocolombianos despojados de sus tierras, un gran daño ecológico y, por supuesto, unas condiciones laborales deplorables...». 
En el año 2004, la empresa A. M. Castle \&Co., domiciliaria en la región de Alberta, en Edmonton, invirtió U\$45 millones en una de las primeras plantas de alcohol carburante en Colombia, ubicada en el Departamento de Boyacá, en el centro del país, en la cual se extraen aproximadamente 150.000 litros por día de etanol.

Aunque no existen datos que vinculen directamente la inversión canadiense en los ingenios azucareros del Valle del Cauca, la ventaja comparativa en la producción de energías alternativas, como lo es el etanol, y el interés en las inversiones canadienses o compras de sectores claves de la agroindustria, cabría esperar un interés especial de empresarios del país norteamericano en este sector favorecido por las exenciones contempladas en el TLC. En efecto, desde septiembre de 2007, el ministro de Agricultura de entonces recibió de un grupo de inversionistas, incluidos algunos del Canadá, manifestaciones de interés en este negocio. Como incentivo, el Gobierno nacional disminuye el impuesto a la renta de $37 \%$ al 15\%. Lo anterior, a pesar de la resistencia de amplios sectores sindicales canadienses y del gobierno de este país, que registra en los documentos de ayuda internacional una sensible inclinación en los temas de agenda, constituyendo una responsabilidad indirecta sobre Derechos Humanos y asistencia social.

Esta relación triangular que muestra, por un lado, los intereses de empresas privadas en búsqueda de réditos económicos entre los dos países, los pronunciamientos de varios sectores de la sociedad civil canadiense, así como el desmedro del Estado colombiano por encarar los distintos problemas sociales relacionados con la actividad cañera, constituyen actores que de manera (in) directa violan los Derechos Humanos y la reproducción de la pobreza.

\section{INCIDENCIA EN LA PRODUCCIÓN Y LA REPRODUCCIÓN DE LA POBREZA}

La investigación realizada por la Universidad San Buenaventura, en la región sur del Valle del Cauca, ha encontrado cómo al amparo de políticos los grandes propietarios se han hecho a beneficios particulares, y señala cómo un reconocido paramilitar: Ever Veloza García, apodado «HH» admitió -que en Caloto Cauca, muy cerca del área de Florida, en el Valle del Cauca, - declararse responsable de haber encabezado y ordenado el asesinato colectivo de 8 personas el 2 de febrero de 2001. Declaró lo siguiente: «...Un señor Mosquera y un señor Lenis fueron quienes más nos apoyaron para que les cuidáramos sus fincas cañeras, mansiones y diversas propiedades en Timba, Cauca, y otros sectores..» (El país, 23 de enero de 2009). De las dos personas mencionadas, el primero de ellos fue ex gobernador del departamento del Cauca, y ex embajador en República Dominicana, y en este momento está judicializado por vínculos con grupos paramilitares por la Justicia de Colombia, El segundo es miembro de una de las familias más tradicionales y adineradas del sur-occidente colombiano.

Lo anterior es una muestra de cómo muchos de los desplazamientos forzados en Colombia son originados por los mismos políticos latifundistas que, a su vez, al ubicarse en sitios de privilegio, establecen relaciones laborales con ingenios azucareros beneficiándolos de esa mano de obra 
barata (y relativamente cuantiosa) que se ha producido por los desplazamientos forzados. Este es el caso del municipio de Florida, ubicado al suroccidente del departamento del Valle del Cauca, en Colombia. (Gráfico 1) Municipio que deriva sus ingresos de una de sus principales actividades agrícolas comerciales, que son las que giran alrededor de las labores propias del trabajo en los ingenios azucareros.

\section{Gráfico 1}

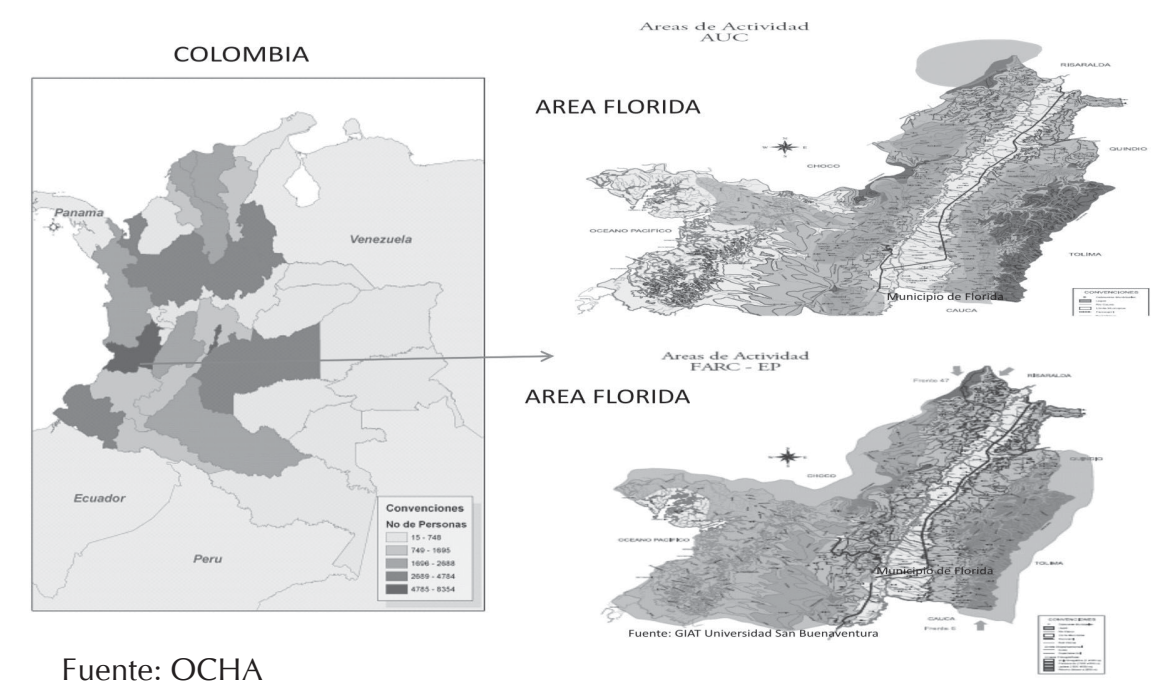

Se da cuenta de ello y se suscribe, por la problemática planteada por la Asociación de Desplazados de Florida, Valle, (ADESFLOVALLE). El 33\% de las familias inscritas derivan su sustento del corte de caña. Las familias han sido desplazadas por los distintos actores de la violencia en Colombia, y son oriundas del departamento del Valle o de departamentos vecinos que no encuentran otra actividad laboral distinta, aunque su ocupación original antes del desplazamiento no sea esa. El $23 \%$ de los entrevistados afirma que ha tenido que aceptar este trabajo, pues no han podido encontrar uno en lo que saben hacer.

Son testimonios de esta situación los siguientes:

«...mi esposo antes trabajaba como agricultor... hay diferencia... este trabajo es muy duro. Él se la pasa todo el día trabajando, los domingos no descansa, le gustaría otro trabajo pero a dónde... aquí en Florida, la mayoría vive de la caña...» Nancy, entrevista 6-01/29.

«... de donde yo vengo [de la Costa Pacífica] yo sé de pescar, de cultivar la tierra... los violentos me sacaron de mi tierra... aquí en Florida se hace lo de la caña y ya no tengo fuerzas...» abuelo, Historia de vida 16-25/07 
Lo preocupante, además, son las difíciles condiciones laborales y las consecuencias en términos de bienestar físico. Un cortero hacía referencia a su salud por la ocupación:

«... me encuentro incapacitado por más de 200 días debido a una lesión en el hombro, en el manguito rotador. A pesar de que tengo toda la documentación al día por parte del Seguro Social, el ingenio se niega a reubicarme en otra actividad laboral distinta a la del corte de caña...» (Germán, 6-01/09).

No es difícil deducir que una persona que ha dedicado 24 de 46 años de su vida a la actividad del corte, como el informante anterior, padezca en su salud los rigores agobiantes de esta actividad ocupacional. Y se muestran casos similares:

«... llevo trabajando de cortero desde 1979, estoy incapacitado desde febrero del año pasado. Me operaron de un tumor en la cabeza... estaba trabajando en el cañaduzal y de un momento a otro me desmayé. Me llevaron a la enfermería, pero como era sábado y no había nadie, me trasladaron a Cali. Ya el lunes desperté, pero no me acordaba de nada de esto... Estoy esperando que me reubiquen en otro trabajo, pero no se sabe. Llevo 28 años cotizando al Seguro Social, y me faltan 4 años para mi pensión...» (Cortero de caña, 6-01/27).

Pero además de que esta ocupación es una de las difíciles en términos de esfuerzo físico ${ }^{9}$ y mal remuneradas, también se comenta cómo la mismísima la muerte ha llegado a los cañaduzales: «... en una ocasión, en pleno corte, un señor se desmayó. Supimos que había muerto días más tarde. Parece ser que el extenuante trabajo al sol y las condiciones de alimentación no eran las mejores... esto persiste en nosotros, la enfermedad y la constante incapacidad...» (Gonzalo, 6-01/09).

Los ingresos que percibe el cortero semanalmente son por la cantidad de caña cortada. Pero, a su vez, ellos no saben cuánta caña cortarán al día por varias razones: desde las climáticas, hasta las relacionadas con el tipo y clase de caña que se sembró en el cañaduzal. Para esto, solamente reciben su salario si se encuentran cortando. «...No queda para la recreación. El cortero no sabe lo que es salir, pues tiene que ir a cortar caña...» Un día que se falte, es dinero que deja de percibir la familia. Por eso, los incapacitados deben recurrir a sus familias y conocidos para lograr el sustento diario:

\footnotetext{
${ }^{9}$ Según Alves, F (2006) un trabajador que corte 6 toneladas de caña en un área de 200 metros de ancho por 8.5 metros de largo, camina durante un día una distancia aproximada de 4.400 metros, después de aproximadamente 50 golpes de machete para cortar un tajo de caña que equivale a 183.150 golpes diarios. Además de golpear la caña, el trabajador debe flexionarse unos $30 \mathrm{~cm}$. en cada golpe, que constituyen aproximadamente 36.630 flexiones de pierna, y debe cargar -si no existe la máquina adecuada- la caña en sus brazos, en tajos de $15 \mathrm{~kg}$., a una distancia que varía de 1.5 a 3 metros, perdiendo unos 8 litros de agua por día. Gran cantidad de energía, por lo tanto, se necesita para caminar, golpear y cargar el peso de la caña, sin contar con la vestimenta apropiada para esto, como lo son: overoles, canilleras, guantes y botas con platina, además de chalinas para protegerse el cuello y la cabeza de insectos y del agobiante calor.
} 
«...Mi papá viene todos los días a comer. Es algo pesado para mi marido y para mí. Es otra carga alimenticia, pero ¿como lo voy a dejar? Yo soy desplazada y él me dio la mano cuando salí de Putumayo. A veces nos toca comer a cada uno de a menos...» (Rita 6-01/27).

Las estrategias familiares y sociales son importantes en términos de sobrellevar sus condiciones generales de vida. En primera instancia, el grupo familiar es aliento y sustento inicial del desplazamiento, así como vecinos, amigos y conocidos trabajan en aras de la supervivencia del colectivo. Relatan cómo en la época difícil del paro se reunían las familias de los corteros en los cañaduzales a realizar «olla en común». Esto es, cada una de las familias se encargaba de llevar alguna clase de alimento para, de esta manera, no dar marcha atrás en sus peticiones y también lograr el sustento mínimo del alimento.

«... salíamos a taponar las vías, pero últimamente a las personas las estaban estropeando... las mujeres madrugaban a no dejar salir a nadie... los policías estropeaban a las mujeres, la gente "rebotada» había quebrado los vidrios a los carros y hasta otros fueron a parar a la cárcel de Timba. Nosotros también íbamos, porque a veces llevaban comida y nosotros... pues ayudábamos a la olla comunitaria... al almuerzo... más los niños, y así no la pasamos nosotros... yo me iba en la cicla... menos mal de vieja me fui en la cicla... así me ahorraba el transporte...» (Nardy, 6-01/09). Son tan precarias las condiciones de los trabajadores de la caña, que el mismo presidente de la República, el señor Uribe Vélez, declaró en la época del paro de corteros: «... el trabajo de corte de caña es un trabajo desarrollado bajo formas de esclavitud contemporánea...»

Las constantes lesiones producidas por su actividad laboral y el exiguo salario reconocido a través de las cooperativas de trabajo asociado que realizan las contrataciones con los ingenios de la zona, además de pauperizar y desmejorar las condiciones de existencia de los trabajadores, se reflejan en las condiciones de pobreza del núcleo familiar. El jefe de hogar, en estos casos los varones, son los encargados de llevar el sustento diario a sus familias ${ }^{10}$.

El trabajo adelantado en las historias de vida y entrevistas estructuradas muestran cómo viven la realidad este sector de clase social y cómo, desde todo punto de vista, se acentúan las condiciones de producción de la pobreza y la violación sistemática de los Derechos Humanos, que continúa sin una pronta solución.

El paro de corteros de caña que inició en el mes de noviembre de 2008, con 56 días de cese de actividades laborales en los principales ingenios azucareros del Valle del Cauca, muestra solamente la punta del iceberg en materia de violación de los mínimos derechos sociales y económicos de sus trabajadores en busca de mejorar sus condiciones de trabajo. Ya en el año 2005 se habían manifestado brotes de inconformidad laboral-salarial ante los ingenios por sus precarias condiciones.

\footnotetext{
${ }^{10}$ Estas y otras cuestiones relacionadas con la situación general de los corteros de caña en el Valle del Cauca bajo contratos laborales de las cooperativas de trabajo asociado (CTA) puede encontrarse en Aricapa R. (2006)
} 
Puntualmente, lo que se reclamó en este último cese de actividades fue alcanzar las mínimas condiciones laborales a las que puede acceder cualquier trabajador: Los aproximadamente 10.000 corteros, reunidos en 102 cooperativas de trabajo asociado, solicitan que la contratación laboral se haga directamente con los ingenios y que se busque la estabilidad laboral. Además, el pago de los días faltados a los cañaduzales por justificación médica y los tres días de incapacidad por enfermedad que no pagan las EPS (Empresas Promotoras de Salud). También solicitan auxilios para educación, vivienda y todas las prestaciones de ley.

Uno de los gerentes de una importante cooperativa de la zona, que reúne alrededor de 517 asociados, manifestó cómo después del cese de actividades de noviembre pasado al 27 de enero se ha visto una desmejora en el tema de pago del corte de la caña. No se han visto los beneficios, puesto que se aumentó el tonelaje (peso de caña para cortar) al igual que su precio. Manifiestan que han venido conversando con el ingenio a ver cómo se puede solucionar este inconveniente, y los días miércoles los representantes legales de la cooperativa se reúnen con los representantes del ingenio para encontrarle salida a esta situación. Estos últimos están muy preocupados, pues piensan que los corteros están tratando de llevar a cabo otro paro ${ }^{11}$. Los asociados a las cooperativas cañeras no quieren hacerlo ni repetir lo que tanto les costó, sólo quieren solucionar las cosas dialogando, porque les es claro que el paro no los beneficia en nada y porque lo que se reclamó se vino abajo.

De esta manera, el sentir general de los corteros es «... uno esta más jodido de lo que estaba antes...». «... cómo se está matando uno para que le paguen a uno esto...» [haciendo referencia a la tirilla de pago en donde se muestra la relación de cantidad y el peso de caña cortada].

Sus ingresos, siete días a la semana durante el mes, pueden ser de alrededor de U $\$ 400^{12}$. Sin embargo, en varias cooperativas, a este monto hay que descontar el $8 \%$ de seguridad social, $4 \%$ de riesgos profesionales, transporte hasta los cañaduzales, administración mensual a la cooperativa (que fluctúa según el tamaño de esta, específicamente por los asociados) y dotación (machetes, canilleras, guantes, etc.) que se paga a la misma cooperativa.

Las manifestaciones generales de apoyo y solidaridad del gremio de los trabajadores a los corteros de caña se hicieron sentir por parte de los canadienses, como se ilustra a continuación:

\footnotetext{
${ }^{11}$ Estimaciones del sector azucarero calculan que la producción en 2008 cayó un $10.6 \%$ por el invierno y el paro de corteros. En el bloqueo de los corteros, 8 de los 13 ingenios dejaron de producir 263.000 toneladas de caña, al igual que 39 millones de litros de etanol y 600.000 toneladas de bagazo, al igual que otros productos que suman unos U\$136.000 millones. (el País, 22 de enero de 2009). Sin duda, un gran golpe a las ganancias de los ingenios azucareros del país.

12 Un cortero con mayor productividad necesariamente debe tener una mayor masa muscular y resistencia física para realizar una actividad repetitiva y exhausta, en algunos casos entre 8 y 12 horas diarias. 
Carta al Presidente de la República de Colombia en manifestación por el paro de corteros de caña, por parte de la Alianza del Servicio Público de Canadá

Toronto, Canadá, 6 de octubre de 2008

Dr. Álvaro Uribe Vélez

Presidente de Colombia

Estimado Sr. Presidente:

La Alianza del Servicio Público de Canadá protesta enérgicamente por los ataques contra más de 10.000 trabajadores de la industria azucarera que actualmente están en huelga en Colombia. Es inaceptable la negativa de ASOCAÑA, de negociar mejores salarios, jornadas de trabajo más cortas, un ambiente de trabajo más saludable, mejores viviendas e instalaciones educativas para los trabajadores y sus familias y un contrato de trabajo formal con derechos laborales y sindicales. Esta situación merece la atención internacional.

Más de 100 trabajadores fueron heridos el 15 de septiembre cuando se ordenó a los militares desalojarlos. [...] La huelga se realiza cuando los productores de caña de azúcar proponen expandir los cultivos para producir biodisel y azúcar. Ya rechazaron considerar mejorar las condiciones de trabajo y salarios que buscaron los trabajadores a través de su organización sindical. Sus acciones están minando a los sindicatos colombianos y muestran su insensibilidad y desprecio por las organizaciones sindicales y los derechos de los trabajadores que buscan mejorar los sueldos y trabajar en condiciones seguras con horarios razonables.

[...] Las acciones de ASOCAÑA y del Gobierno colombiano violan los derechos más fundamentales inscritos en la Declaración de los Derechos Humanos de las Naciones Unidas y las convenciones de la Organización Internacional del Trabajo, firmados por el Estado colombiano.

Durante mi reciente visita a Colombia, el Dr. Fabio Valencia Cossio, Ministro del Interior, y el Sr. Andrés Fernando Palacio Chaverra, Viceministro de Relaciones Laborales, declararon que el respeto a los derechos de los trabajadores ha mejorado. Lamentablemente, los ataques contra los líderes sindicales y activistas se han incrementado considerablemente desde mi visita en julio. Los recientes ataques contra los trabajadores azucareros en huelga indican que su gobierno está determinado a ignorar los derechos laborales y humanos más básicos. Esas acciones por parte de su gobierno hacen más evidente que Canadá no debe firmar e implementar un tratado comercial con Colombia.

Sinceramente

John Gordon

Presidente Nacional [Sindicatos de Canadá] 


\section{CONCLUSIONES}

¿Cómo se constituye la producción de la pobreza y la violación de los derechos humanos?

Como se mencionó anteriormente, el poder económico de los ingenios en el área señalada del sur occidente del Valle del Cauca, Colombia, influye directamente sobre las actividades económicas, sociales y políticas de la región. Las relaciones de intercambio comercial en este caso protegen y acentúan las ganancias en cuanto los Estados avalan las condiciones laborales y las actividades de ciertos miembros de la sociedad o agentes en relación con ellos en la concentración del capital.

En este sentido, a pesar de las manifestaciones de los sindicatos de trabajo de Canadá, más parecen prevalecer los beneficios a unos pocos que al bienestar general de un grupo de la población. Las demandas de energías alternativas, como lo es el alcohol carburante por parte de Canadá, seguramente acentuará la condición de precariedad de la población rural, no solamente desplazada sino residente en los cluster azucareros, convirtiéndose en actores indirectos a la violación, producción y reproducción de la pobreza. En este caso especifico, la población desplazada no solamente soportó el destierro, la violencia y la pérdida de los activos dejados en sus sitios de origen sino que también, después de su desplazamiento, sufrió los rigores de la explotación, la marginación y pauperización en los sitios de recepción.

Con respecto a los Derechos Humanos, pareciesen primar principalmente la relación entre individuos frente a las responsabilidades del Estado. Sin embargo, en el caso de la pobreza global, también se señalan y se muestran las responsabilidades de otros Estados que en el margen de la cooperación y asistencia internacional se les pueden atribuir responsabilidades, pues a estos últimos se les debe exigir relaciones más equitativas entre los miembros de la sociedad mundial.

Este proceso del estudio de caso mencionado es una muestra de la violación de los Derechos Humanos y, por lo tanto, debe conducir a señalar y detectar algunas cuestiones sugerentes ligadas con la producción y reproducción de la pobreza:

- Que hay más cortadores de caña disponibles y en busca de trabajo, como resultado de un aumento en los desplazamientos forzados en la zona. Además del creciente desempleo del país, los grupos etáreos del desplazamiento indican cómo los jóvenes cuyas edades oscilan entre los 12 y los 20 años se convierten en la población más vulnerable.

- La presión creada por las condiciones de trabajo, expresadas por las demandas internacionales y acuerdos de cuotas de exportación de las empresas azucareras.

- La imposibilidad del Estado de controlar, verificar y garantizar el efectivo reclamo de los trabajadores corteros.

- $\quad$ El interés de los grandes capitales, las elites regionales y de los Estados de mantener un orden global injusto que beneficia a unos pocos y perjudica a muchos. 


\section{BIBLIOGRAFÍA}

ALVES, F (2006) «¿Por que morrem os cortadores de caña?» En: Pastoral do migrante. Qua, 01 de marzo. Sao Paulo, Brasil.

- $\quad$ ARICAPA, R. (2006) Las CTA del sector azucarero: ¿Flexibilización o salvajismo laboral? En publicación: Revista Cultura y Trabajo, no. 69. ENS, Escuela Nacional Sindical: Colombia, octubre.

- CEPAL (2002) «El conglomerado del azúcar del Valle del Cauca, Colombia». Centro Nacional de Productividad. Santiago de Chile, diciembre.

- DE VITa, A. (2003:226). "La teoría de Rawls de la justicia internacional». En: A. Boron, Filosofía política contemporánea. Controversias sobre civilización, imperio y ciudadanía, 221-258. Buenos Aires: CLACSO.

- CIMADAMORe, A. (2005). «Prefacio», en Sonia Álvarez Leguizamón (comp.), Trabajo y producción de la pobreza en Latinoamérica y el Caribe: estructuras, discursos y actores. Buenos Aires: CLACSO.

- $\quad$ ESPINAL C, MARTíNEZ C, y Beltrán L (2005) «La agroindustria del azúcar en Colombia». En: Agrocadenas. Observatorio de Competitividad Agrocadenas. Documento de trabajo N. 50. Ministerio de Agricultura. Bogotá.

- $\quad$ GUEVARA, D. (2007) «El doble desafío en busca de un mejor futuro: jóvenes y desplazados en Colombia». En: Medio Ambiente y Urbanización, Vol.69, No.1 55-66

- $\quad$ GUEVARA, R. (2008). «Violencia y desplazamiento: características de las mujeres desplazadas jefas de hogar del municipio de Florida. Valle del Cauca. En: Reflexión Política. Instituto de Estudios Políticos. Universidad Autónoma de Bucaramanga. Año 10 No 20. 154-174.

- $\quad$ JOCHNICK, C. (2001). «The Human Rights Challenge to Global Poverty». In w. Van Genugten, \& C. Pérez-Bustillo, The Poverty of Rights. Human Rights and the Erradication of Poverty 159-183 New York: CROP.

- $\quad$ LUNA, F. (2007). "Pobreza en el mundo: obligaciones institucionales y derechos humanos» Revista latinoamericana de filosofía vol 33 N.2 239-314.

- MACHADO, A. (2004) «Tenencia de la tierra, problema agrario y conflicto». En M. Bello. (editora), Desplazamiento forzado, dinámicas de guerra, exclusión y desarraigo 81-96. Bogotá: ACNUR-Universidad Ncional de Colombia. 
- $\quad$ MONDRAGÓN, H (2008) «Caña de azúcar y palma aceitera, biocombustibles y relaciones de dominación». Centro de Cooperación Indígena, Cecoin, Bogotá.

- Pérez-Bustillo, C (2001) «Expansion of citizenship and Democratic Construction». In w. Van Genugten, \& C. Pérez-Bustillo, The Poverty of Rights. Human Rights and the Erradication of Poverty 159-183. New York: CROP.

- POGGE, T. (2005 a). «Severe poverty as a violation of negative duties». Ethics and International Affairs, 55-84.

- $\quad$ POGGE, T. (2005 b). La pobreza en el mundo y los derechos humanos. Barcelona: Paidos.

- SARMIENTO, L (2000) «Desarrollo societal, conflicto y territorio». Ponencia presentada al Seminario Internacional Desplazamiento, conflicto, paz y desarrollo, 30 de mayo a 2 de junio de 2000. Bogotá: Codhes.

- VAN GENUGTEN, W., \& Pérez-Bustillo, C. (2001). The poverty of rights. Human rigths and the erradication of poverty. New york: CROP. 